\title{
Snapshot
}

\section{Birthmarks: phacomatosis pigmentovascularis}

A 36-year-old Chinese man had been born with multiple coloured lesions on his face, sclera, neck, trunk and limbs. Physical examination revealed extensive capillary malformations (naevus flammeus or port wine stain) on his neck, chest, back and upper limbs (Figure, A). Bluish-grey macules involved the left V2 dermatomal distributions of his face and conjunctiva, consistent with naevus of Ota and melanosis oculi (Figure, A). Aberrant Mongolian spots were present on his trunk (Figure, B and C). No other positive findings were noted. A diagnosis of phacomatosis pigmentovascularis (phacomatosis cesioflammea form) was made.

Phacomatosis pigmentovascularis is defined as the coexistence of an extensive vascular naevus and various melanocytic lesions. ${ }^{1}$ It is estimated that $50 \%$ of patients with phacomatosis pigmentovascularis have systemic involvement, particularly of the eyes and central nervous system. ${ }^{1,2}$ No systemic involvement was evident in this patient.

Jianjun Qiao Dermatologist

Hong Fang Dermatologist

The First Affiliated Hospital, College of Medicine, Zhejiang University, Hangzhou, Zhejiang, China. fanghongzy@sina.com
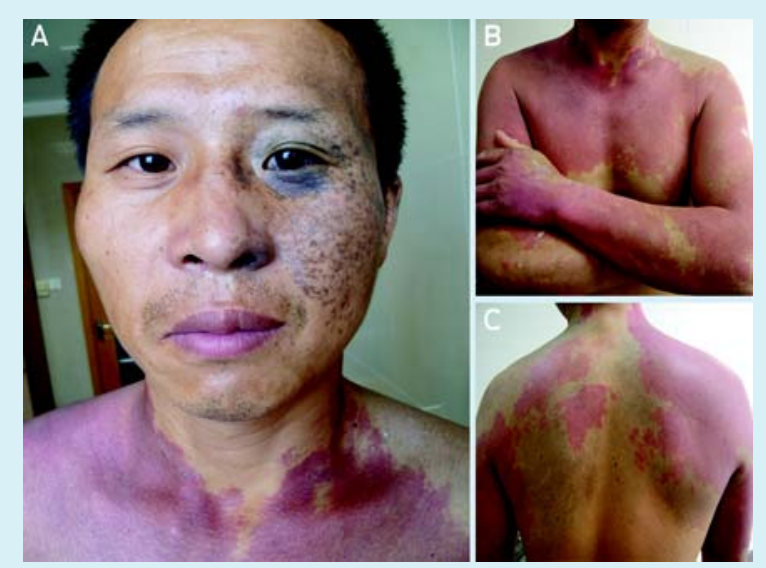

1 Fernandez-Guarino M, Boixeda P, de Las Heras E, et al. Phakomatosis pigmentovascularis: clinical findings in 15 patients and review of the literature. J Am Acad Dermatol 2008; 58: 88-93.

2 Happle R. Phacomatosis pigmentovascularis revisited and reclassified. Arch Dermatol 2005; 141: 385-388.

doi: $10.5694 /$ mjall.10720 